\title{
Research on Talent Training and Social Demand of Sports Industry in Jilin Province
}

\author{
Wang Qingbao \\ Baicheng Normal University, Baicheng, 137000, China \\ wqb1105@163.com
}

Keywords: Sports Industry, Talent Training, Social Demand, Leisure Sports

\begin{abstract}
Under the current situation, the social development needs more and more talented persons with comprehensive quality. In the process of cultivating talents in sports industry, managers need to train students or learners to master the basic knowledge of humanities and social sciences, as well as management and economy, on the basis of actual industrial development and social needs. At the same time, they also need to have sports industry related organizational management and guidance and consultation and other knowledge. How to effectively grasp the difference and common ground between the talent training of sports industry and the social demand is the problem that should be paid attention to in the training of sports industry talents at present. Based on this, the research and analysis are carried out in this paper.
\end{abstract}

\section{Introduction}

With the continuous development of the society, the sports industry is becoming more and more comprehensive, and the social sports industry needs more and more complex talents in the aspects of sports industry management, sports event planning and organization and management. The training of talents in colleges and universities is usually aimed at teaching and organizing management of high complex talents and social applied talents needed for the development of middle society. This paper analyzes the current situation of social sports industry talent training and social demand, and carries out research and analysis on social sports industry professional social demand, and makes a comparative analysis on the orientation of social sports industry specialty training goal and social demand. The author hopes to enlighten the training and teaching of sports industry talents.

\section{Analysis of the Present Situation of Talent Training and Social Demand in Social Sports Industry}

\subsection{Analysis of talent training goal and curriculum arrangement}

In the current situation, the social development needs more and more talents with comprehensive quality. In the process of cultivating sports industry talents, it is necessary to combine the actual industrial development with the actual social needs as the basis [1]. To train students or learners to master the basic knowledge of humanities and social sciences, as well as management and economics, as well as knowledge of organization, management, guidance and consultation related to the sports industry, the sports industry is becoming more and more comprehensive. The trained talents need to master the complex talents in the aspects of sports industry management, sports competition planning and organization and management. In the actual management of colleges and universities, the training of sports industry talents also pays more attention to the training of the comprehensive quality of the learning objects. The training of talents is usually aimed at teaching and organizing management of high complex talents and social applied talents which are needed for the development of middle society. After nearly ten years of development, the physical education major has continuously established and perfected the physical education curriculum. In the actual personnel training process, more attention should be paid to the cultivation of students' basic skills 
and knowledge of mass sports fitness, as well as sports marketing, sports industry organization and management, leisure sports, etc. On the basis of mastering the basic knowledge of physical education, the students should improve their ability of application and organization of sports knowledge, which has an important influence on the comprehensive development of physical education learners [2].

The cultivation of talents in sports industry not only needs to set up the training plan according to the teaching goal of physical education, but also combines the reality of social development to train the complex sports talents needed for the social development. In the process of cultivating sports talents, colleges and universities should constantly improve the training methods of sports industry personnel and the teaching of college talents, at the same time, they should set up a talent training model based on the needs of social development in combination with the goal of talent training [3]. To ensure that the students and sports talents can meet the needs of social development, and to help students improve their comprehensive quality competitiveness.

\subsection{Analysis on social practice link}

Sports industry is an important component of sports discipline. Sports industry is the combination of the current situation of social development and rising. People pay more and more attention to the benefits of sports, so the whole sports industry serves the vast number of social sports participants. In accordance with the provisions of the syllabus and the needs of social development, colleges and universities plan their professional practice into the training of talents in the sports industry, and gradually increase their support for the cultivation of talents in the sports industry. The optimization and improvement of social practice plan are carried out in combination with the change of social development demand effectively. This social practice mode has a positive effect and influence on the cultivation of talents in sports industry. Paying attention to social practice teaching in the process of cultivating sports talents in colleges and universities can not only help students master more solid knowledge of sports theory and skills, but also help students to improve their social adaptability and competitiveness. Let students master more social experience and lay a good foundation for future work and life. In the current situation, the social practice in the cultivation of sports talents in colleges and universities has just started. In carrying out social practice, there are many problems, such as lack of base, lack of time and single practice, which affect the development of social practice. Also causes the student to the sports industry's cognition and the understanding existence deviation [4]. So we should pay attention to the cultivation of students' social practical ability in the process of cultivating college sports industry talents, which can not only conform to the development law of the times, but also help the students' physical education study to adapt to the social development.

\section{Study on the Social Demand of the Specialty of Social Sports Industry}

\subsection{The demands of social sports units on the comprehensive quality of sports industry talents}

At the present stage, the level of economic development in our country is getting higher and higher, people's living standards are gradually improving, the people's demand for sports is becoming more and more diversified and modernized, and the modern people's awareness of physical exercise is becoming more and more high. The majority of the people are actively involved in sports fitness, people's demand for sports items is increasing, and the requirements for sports industry professionals have also been raised [5]. The author has learned that the employment direction of the graduates of sports industry is more inclined to the field of mass sports, more reflected in the guidance of social sports and the mass sports and sports industry related fields. At present, the development of social sports industry is still in its infancy. The organization and management of students majoring in sports industry involves many problems. Therefore, in the process of cultivating sports industry talents, we not only convey to the students the theoretical knowledge of sports comprehensive specialty, but also the relevant social practice ability and technical skills. At the same time, we also need to guide students to master interpersonal 
communication, project organization and management, and team work. At the same time, students are required to master the skills of text editing and computer technology to better meet the needs of social development.

\subsection{Investigation on the actual demand of social sports industry talents for social development}

The state and the government issued and implemented the national fitness development plan. In the actual development plan, the state has also made certain provisions on the development of social sports instructors, which requires strengthening the construction of the contingent of social sports instructors and advocating the building of a national fitness team. To establish and improve the fitness guidance station and strengthen the construction of sports organization clubs, and to promote the construction of community sports fitness points. At the same time, in the development of social sports, it is necessary to continuously attract and organize social sports guidance staff to join the social sports instructors through policies and guidelines, and constantly promote the improvement of the technical grade of social sports instructors. This kind of sports development regulation can see the state and the government's development determination, its important strategy to the sports industry talented person's attention degree unceasingly enhances [6]. In recent years, the residents' fitness activities of the general public have been developing continuously. Most of the sports activities are usually made up of the elderly, but at the present stage the sports instructors are unable to meet the needs of social sports. The proportion of sports instructors and sports personnel is seriously out of balance, and the management of sports facilities and professional guidance personnel are relatively lacking, which also shows that the sports industry needs a wide range of talent space.

\subsection{The potential demand of social sports guidance and management professionals in the field of leisure sports}

With the development of socialist market economy, people's living standard and economic level have been improved continuously. On the basis of material life satisfaction, people pay more and more attention to the pursuit of spiritual life. On the basis of sufficient time and economic level, people's pursuit of life style is also increasing, not only to satisfy the abundance of material life, but also to the pursuit of physical and mental satisfaction. The social leisure sports domain covers many aspects, the social development impels people to pursue the quality of life unceasingly, the social leisure sports conforms to the modern resident's sports need, the leisure sports often revolves around the sports entertainment development. Influenced by the change of market demand. In general, influenced by the trend of aging, people pay more attention to leisure sports, and the attention of middle-aged and elderly people and women to leisure sports is also increasing. More and more people pay attention to the function of sports rehabilitation and health care in leisure sports. Some studies have shown that, no matter how the economic development, people's demand for entertainment is unchanged, so in the face of the increasingly developing social situation, the sports industry in the leisure sports field also has a huge space for development.

\section{Comparative Analysis on the Orientation of Training Objectives and Social Needs of the Specialty of Social Sports Industry}

\subsection{The difference between the training goal of professional talents and the demands of the society on the comprehensive quality of professional talents}

At present, the development of social sports industry is becoming more and more diversified and comprehensive. Therefore, the community sports fitness guidance, the leisure sports complex industry and the sports industry peripheral fields are demanding more and more talents based on the development of this kind of social sports [7]. The talent training in the social sports industry has a high degree of conformity with the social needs, but in fact, the graduates majoring in the sports industry are not recognized by the social sports, and the public lacks the cognition of the social sports instructors. It is difficult to meet the needs of graduates in social sports. With the continuous 
development of social sports, the degree of professional training in the sports industry is increasing, and the development trend of mutual influence is inevitable for the development of social sports. Under the current situation, the cultivation of talents in sports industry does not fully reflect the needs of the development of social sports industry, which leads to the fact that students majoring in sports industry do not form a scientific and efficient effect in the process of applying their actual knowledge to social sports. In the process of social sports development, the knowledge of talent training and organization management is not fully utilized.

Graduates majoring in sports industry often have a certain gap with the professional quality and ability requirements of relevant units in sports industry. Even so, leisure sports has a broad development space and prospects, but limited by the mode of professional education, resulting in the social sports industry personnel training process has not been set to adapt to the curriculum. Only a few colleges and universities offer teaching courses in the field of leisure sports and pay little attention to the cultivation of talents in leisure sports. Therefore, it is necessary to strengthen the training of professionals in this field and constantly improve the training objectives of talents. According to the needs of the development of social sports, we should train talents and improve the students' ability of social practice and knowledge application [8].

\subsection{The comparison of curriculum setup, social practice and market demand}

With the continuous development of social sports, it is an important content to train the sports industry talents by combining the humanities and social sciences, natural science and comprehensive science. On the basis of the actual needs of social sports development, there is no scientific and reasonable setting of professional skills and basic theoretical knowledge related to the development of social sports, as well as sports industry and leisure sports. Therefore, colleges and universities in sports industry in the training of talents and not to train sports marketing and sports industry management and leisure sports field needs a high degree of integration talent. In view of this situation, colleges and universities for the sports industry specialty curriculum design needs to be in accordance with the needs of social sports development targeted to set up a talent training curriculum program, so that students' sports professional ability more prominent, Constantly cultivate the sports industry comprehensive management and sports basic knowledge and technology application of composite talents. Under the current situation, the demand for talents in the development of social sports is increasing, and the experience of social practice has a great influence on the students' professional knowledge and technical application ability. In the process of cultivating talents in sports industry, the students also lack the opportunity of social practice because of the lack of corresponding sports facilities. In addition, due to the late start of professional teaching in the social sports industry, it is difficult for students to have the resources of social practice, which leads to the lack of opportunities for students' social practice. It also leads to the social practice effect of students majoring in social sports industry is difficult to meet the needs of social sports development.

\section{Conclusion}

With the continuous development of the society, the sports industry is becoming more and more comprehensive, and the social sports industry needs more and more complex talents in the aspects of sports industry management, sports event planning and organization and management. In the teaching process of sports industry in colleges and universities, the training of professional talents of sports industry is often oriented to the teaching and organization management of high complex talents and social applied talents needed for the development of middle society. Therefore, it is necessary to analyze the goal, curriculum and social practice of talent training in social sports industry and the current situation of social demand. It also comprehensively grasps and fully studies the demands of social sports units on the comprehensive quality of sports industry talents, the actual demand of social sports industry talents for social development and the potential demand for social sports guidance and management professionals in the field of leisure sports. In order to improve the quality and teaching effect of social sports industry, it is clear that the training goal of professional 
talents is different from the demands of the society on the comprehensive quality of professional talents, and the professional curriculum, social practice and market demand are analyzed in order to improve the quality and effect of teaching in the social sports industry.

\section{References}

[1] WU Liang, ZHANG Jun. Some problems and Optimization Strategies in the Cultivation of Social Sports Guidance and Management Specialty -Taking Guangdong University as An Example [J]. Journal of Zhaoqing University, 2018, 39(05):86-91.

[2] LIU Meng, MA Hongmei. Research on Physical Education Specialty Teaching and Sports Talent Training in Colleges and Universities [J]. Journal of Brand Research, 2018(02):208-209.

[3] ZHANG Pei, ZHAO Zhipeng, YUAN Gengshen, ZHANG Qian, ZHOU Wenjing. Research on the Training Mode of Sports Industry Management Talents in Hebei Province from the Perspective of Beijing-Tianjin-Hebei Cooperative Development [J]. Sport, 2018(15):8-9+22.

[4] HAN Lu. Present Situation and Countermeasures of Physical Education Specialty in Higher Vocational Colleges of Guangdong Province [J]. Journal of Physical Education, 2018, 25(04): 110-115.

[5] LI Zhenjing. Research on Curriculum Setup of Sports Industry Marketing Specialty in Higher Vocational Colleges: A Case Study of Sports Industry Marketing Specialty in Guangdong Vocational College of Science and Technology [J]. Bulletin of Sport Science \& Technology, 2018, 26(07): 30-31.

[6] SONG Ping. Opportunities and Challenges: Reflections on the Cultivation of Fitness and Bodybuilding Professionals under the Background of Vigorously Developing Sports Industry [J]. Journal of Nanjing Sport Institute, 2018, 1(04):27-32.

[7] SHAO Ting. A Preliminary Study on the Matching Between the Cultivation of Sports Industry and Management Personnel and the Social Demand in Colleges and Universities in China [J]. Contemporary Sports Technology, 2017, 7(33):207+209.

[8] ZHAO Jing. Research on the Cultivation and Social Demand of Sports Industry and Public Service Talents in Sichuan Province [J]. Sports World (Scholarly), 2017(08):37-38. 